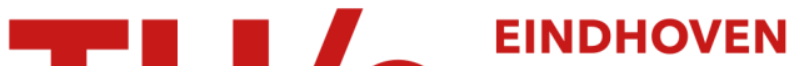 UNIVERSITY OF TECHNOLOGY
}

\section{Four-wave-mixing-based dual-wavelength conversion in a semiconductor optical amplifier}

Citation for published version (APA):

Gallep, C. M., Dorren, H. J. S., \& Raz, O. (2010). Four-wave-mixing-based dual-wavelength conversion in a semiconductor optical amplifier. IEEE Photonics Technology Letters, 22(21), 1550-1552.

https://doi.org/10.1109/LPT.2010.2068284

DOI:

10.1109/LPT.2010.2068284

Document status and date:

Published: 01/01/2010

\section{Document Version:}

Publisher's PDF, also known as Version of Record (includes final page, issue and volume numbers)

\section{Please check the document version of this publication:}

- A submitted manuscript is the version of the article upon submission and before peer-review. There can be important differences between the submitted version and the official published version of record. People interested in the research are advised to contact the author for the final version of the publication, or visit the $\mathrm{DOI}$ to the publisher's website.

- The final author version and the galley proof are versions of the publication after peer review.

- The final published version features the final layout of the paper including the volume, issue and page numbers.

Link to publication

\section{General rights}

Copyright and moral rights for the publications made accessible in the public portal are retained by the authors and/or other copyright owners and it is a condition of accessing publications that users recognise and abide by the legal requirements associated with these rights.

- Users may download and print one copy of any publication from the public portal for the purpose of private study or research.

- You may not further distribute the material or use it for any profit-making activity or commercial gain

- You may freely distribute the URL identifying the publication in the public portal.

If the publication is distributed under the terms of Article 25fa of the Dutch Copyright Act, indicated by the "Taverne" license above, please follow below link for the End User Agreement:

www.tue.nl/taverne

Take down policy

If you believe that this document breaches copyright please contact us at:

openaccess@tue.nl

providing details and we will investigate your claim. 


\title{
Four-Wave-Mixing-Based Dual-Wavelength Conversion in a Semiconductor Optical Amplifier
}

\author{
Cristiano M. Gallep, Member, IEEE, Harmen J. S. Dorren, Member, IEEE, and Oded Raz, Member, IEEE
}

\begin{abstract}
The simultaneous wavelength conversion of two different formats or bit-rate optical signals, with low input power, is demonstrated in a highly nonlinear semiconductor optical amplifier with a single strong continuous-wave pump. For two amplitude-modulated signals of different bit rates, moderate penalties are obtained, and for the case of mixed amplitude and phase modulation at $10 \mathrm{~Gb} / \mathrm{s}$, practically penalty-free operation is achieved. In all cases, small difference $(<1.1 \mathrm{~dB})$ between single- and dualchannel operation is obtained, allowing asynchronous operation.
\end{abstract}

Index Terms-Nonlinear optics, optical frequency conversion, semiconductor optical amplifiers (SOAs).

\section{INTRODUCTION}

A LL-OPTICAL wavelength converters (AOWCs) are likely to become essential building blocks for future dynamic high-capacity optical networks [1]. Wavelength conversion is used as an alternative to unavailable photonic memories, trying to solve contention resolution, as well as for space switching in wavelength-routed networks [2]. In many switch implementations which include a wavelength converter it is considered a scarce resource, often shared between all possible inputs and outputs [3]. It is, therefore, desirable to utilize this resource as best as possible. The ideal wavelength converter should posses many properties, paramount among which are the following:

1) transparency to the modulation format and speed of the incoming data signal, so that the exact same component can be reused regardless of the incoming data signal;

2) compact form factor and integrable technology, so that the converter can be placed on a photonic integrated chip (PIC) together with other components such as switches and filters;

3 ) simultaneous and preferable asynchronous conversion of more than one signal.

Parametric converters based on degenerate four-wave mixing (FWM) using periodically poled $\mathrm{LiNbO}_{3}$ devices [4] as well as highly nonlinear fiber (HNLF) [5] certainly offer transparent

Manuscript received March 01, 2010; revised July 21, 2010; accepted August 08, 2010. Date of publication August 19,2010; date of current version October 01, 2010. This work was supported in part by the Netherlands Science Foundation (NWO), in part by the Netherlands Technology Foundation (STW), in part by Erasmus Mundus' Euro-Brazilian Windows (EBW), in part by the Center for Optics and Photonics (CEPOF/FAPESP), and in part by FotoniCom- CNPq (Brazil).

C. M. Gallep is at the Division of Telecomm. Technology-School of Technology, State University of Campinas, Limeira/SP, 13484-332, Brazil (e-mail: gallep@ft.unicamp.br).

H. J. S. Dorren and O. Raz are with COBRA Research Institute, Eindhoven University of Technology, Eindhoven, NL-5600 MB, The Netherlands (e-mail: O.Raz@tue.nl).

Color versions of one or more of the figures in this letter are available online at http://ieeexplore.ieee.org.

Digital Object Identifier 10.1109/LPT.2010.2068284 converters, yet they do not allow PIC-like integration. Converters based on cross-gain and cross-phase modulation (XGM, XPM) in semiconductor optical amplifiers (SOAs) can be operated at very high speeds [6] and have great integration potential but offer a simple conversion mechanism only for a single amplitude modulated signal, although inclusion of SOAs in more elaborate setups has yielded a more generalized convertor, suitable for either phase or amplitude modulated signal, yet still incapable of simultaneous conversion [7].

The use of SOAs with FWM has several demonstrations [8], [9]; in many of them, a strong optical data-carrier is converted to one or many (multicast) output carriers, achieving high efficiency FWM but with a single data pattern being copied each time. Multiple conversions using a single strong continuouswave $(\mathrm{CW})$ pump and multiple modulated carriers was suggested but only demonstrated for a single modulation format, at low bit rates and with considerable penalty [10]. Recently, we reported on initial results of penalty free simultaneous conversion of two $10-\mathrm{Gb} / \mathrm{s}$ data signals, one modulated in phase and the other in amplitude [11].

In this letter, we expand the concept of FWM-based simultaneous conversion and show that using this method, we obtain an integrable converter, which is transparent to both modulation format and modulation speed and can be operated in an asynchronous manner.

Three different test cases are explored. The case of two $10 \mathrm{~Gb} / \mathrm{s}$ with different modulation format, phase-shift keying and amplitude-shift keying (PSK + ASK) is revisited followed by a complementary scenario of two different bit-rate channels using amplitude modulation, $20+10 \mathrm{~Gb} / \mathrm{s}$ and $40+10 \mathrm{~Gb} / \mathrm{s}$. In all three cases, only small input powers are needed for the incoming data channels, most appropriate in cases were wavelength conversion is required to solve contention in an all-optical switching node [12]. The use of a strong CW pump clamps the optical gain, suppressing the normally occurring XGM. Practical penalty-free operation $(<0.3 \mathrm{~dB})$ is obtained for the case of two $10-\mathrm{Gb} / \mathrm{s}$ signals with different modulation format. When two amplitude-modulated signals with different bit rates are converted, a moderate penalty is found (maximum $<4 \mathrm{~dB}$ ). Most importantly for all the test cases is that only a small difference $(<1.1 \mathrm{~dB})$ between single- and dual-channel operation was measured, implying that the converter can also be used in an asynchronous fashion, as the introduction of a second channel has a minor effect over the conversion performance.

\section{EXPERIMENTAL DEMONSTRATIONS}

The key to the successful demonstration of simultaneous conversion of two independent data signals using FWM is proper power equalization of the input data signals as well as of the strong 


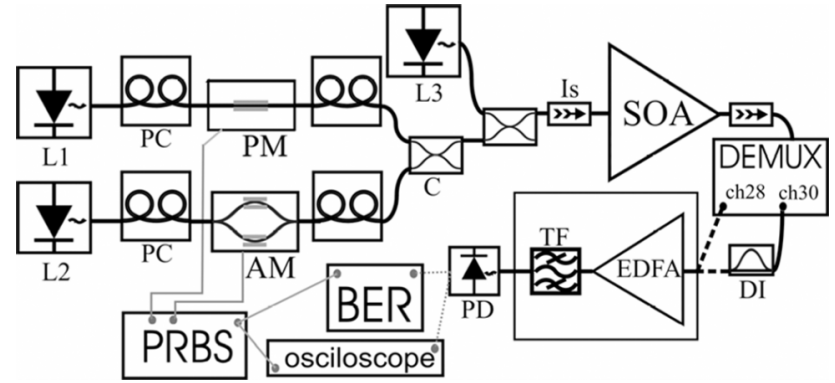

Fig. 1. Experimental setup for dual-channel (PSK + ASK) simultaneous lambda-conversion in a single SOA.

CW pump. Low optical power for the two input channels prevents deleterious FWM products from interfering with the input channels or with the converted products. However, higher input powers improve the optical signal-to-noise ratio (OSNR) of the converted channels, which is essential for error-free operation. Above the optimal input power levels, used in the experiments described below, any increase in the modulated inputs does not enhance the performance but decreases the FWM efficiency due to power splitting into the nondegenerated and secondary FWM products. Similar considerations are also applied to the choice of CW-pump power: the pump must be strong enough to clamp the gain, minimizing any XGM that might be introduced by intensity modulated data inputs, and to reduce the ASE floor.

The equalization process was carried out by monitoring the output eye patterns for residual XGM and bit-error rate (BER) for sufficient OSNR. This process was repeated for both single and dual conversion operation, so that final choice of power levels was a compromise between single and dual conversion. In some cases, single conversion performance could have been much better but also the performance difference between single and dual conversion would have been much larger. The choice of wavelengths (ITU channels) took into consideration the effect of unwanted conversion products between the pump and the data channels. In general, the most suitable arrangement of data channels and CW pump was found to be such that the data channels are up-converted and that the spacing between them is twice as that of the spacing between the CW pump and the data channel closest to it [CW at ITU(X), Data 1 at ITU(X-1), Data 2 at ITU (X-3)]. Implementation of down-conversion schemes (conversion to longer wavelengths) is not possible due inferior OSNR, up to $10 \mathrm{~dB}$ lower than that achieved for up-conversion, due to intrinsic higher ASE floor.

\section{A. Mixed Modulation Formats $10 \mathrm{~Gb} / \mathrm{s}(A S K+P S K)$}

Fig. 1 presents the experimental setup used for the case of PSK and ASK simultaneous conversion at a bit rate of $10 \mathrm{~Gb} / \mathrm{s}$ in both channels.

The two laser sources at $1558.17 \mathrm{~nm}(-12 \mathrm{dBm})$ and $1556.55 \mathrm{~nm}(-17 \mathrm{dBm})$, ITU channels \#24 and \#26, were modulated with PSK and ASK, respectivly, at a rate of $10 \mathrm{~Gb} / \mathrm{s}$ (NRZ PRBS $2^{31}-1$ data sequence) and combined at the SOA input with a much stronger CW signal at $1555.75 \mathrm{~nm}$ (channel \#27). The polarization controllers (PCs) after the lasers were carefully adjusted to achieve the lowest insertion loss through the modulators, and the PCs just after them are used to align the polarization of the $\mathrm{CW}$ pump with the probe signals to maximize the FWM process. The SOA, ultranonlinear device with MQW
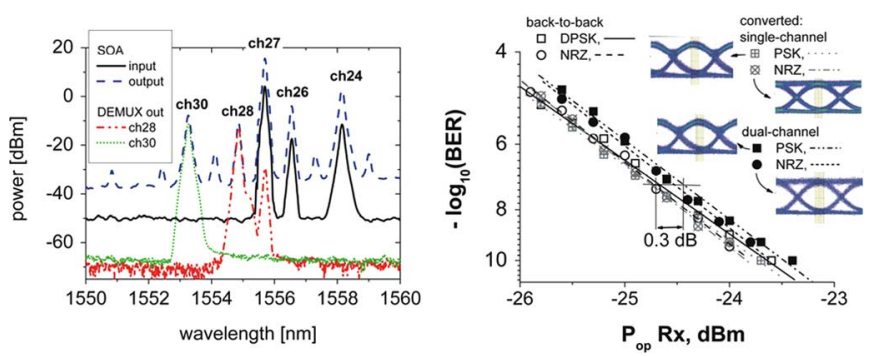

Fig. 2. Simultaneous lambda-conversion, $10+10 \mathrm{~Gb} / \mathrm{s}(\mathrm{PSK}+\mathrm{ASK})$ : optical spectra for SOA input and output, DEMUX channels \#28 and \#30 (left); eye diagrams and BER curves for single and dual conversion operation.

structure (CIP), was biased at $500 \mathrm{~mA}$, with a saturation output power of $15 \mathrm{dBm}$ and small signal gain $>30 \mathrm{~dB}$. At the output, the converted channels were filtered by an ITU-grid DEMUX (100-GHz spacing). To enable the BER versus received optical power measurements in similar conditions, the back-to-back and the converted signals were amplified by a low noise EDFA (10-dB gain, 4-dB noise figure) and filtered again (1.5-nm window) to remove excessive ASE. The converted PSK signal was further processed by passing through a delayed interferometer (DI) to convert phase into amplitude modulation before detection. For the $10+10-\mathrm{Gb} / \mathrm{s}$ case, the BER measurements were taken using a $10-\mathrm{Gb} / \mathrm{s}$ APD receiver.

The optical spectrum at the SOA's input and output as well as the eye diagrams and the BER versus optical power at the receiver for the $10+10 \mathrm{~Gb} / \mathrm{s}$, ASK + PSK, are shown in Fig. 2. BER versus received optical power performance of a single converted channel is as good as the original data signal (back-toback). Even in the presence of a second converted channel the observed degradation is within the measurement error and in any case does not exceed $0.3 \mathrm{~dB}$.

The spectra at Fig. 2 (left) illustrates the required spectral positioning of input data channels and CW pump, as discussed before CW at ITU-grid channel \#27, the ASK channel \#26 PSK channel \#24, avoiding interfering cross-channel products. The input PSK channel required more power $(+5 \mathrm{~dB})$ than the ASK channel since the FWM efficiency drops the further the signal is detuned from the CW pump. In any case, this penalty-free performance is obtained for low input peak powers $(<-10 \mathrm{dBm})$ and a very modest $-2-\mathrm{dBm}$ CW pump.

\section{B. Mixed Bit-Rate ASK $(10+20 \mathrm{~Gb} / \mathrm{s}, 10+40 \mathrm{~Gb} / \mathrm{s})$}

The setup used for mixed bit-rate ASK signals required several minor adaptations in comparison to the setup in Fig. 1. An amplitude modulator (AM) after L2 replaced the phase modulator (PM) and a 40-Gb/s PIN photodetector replaced the APD receiver for all measured BER curves (also for the $10-\mathrm{Gb} / \mathrm{s}$ channels). In addition, the selected wavelength channels were slightly shifted in the ITU grid, but maintaining relative positioning: the CW pump at channel \#28 (1554.94 nm) and the two modulated carriers at channels \#27 (1555.75 nm, L1) and \#25 (1557.36 nm, L2). This shift was required to better align the outputs to a 200-GHz DEMUX used to filter the converted channels out. Fig. 3 shows the measured BER versus received power for NRZ converted channels at 10 and $20 \mathrm{~Gb} / \mathrm{s}$ using a $2^{31}$ - 1-bit-long PRBS data sequence. Optimal input power levels for data carriers were found to be below $-15 \mathrm{dBm}$ and the CW pump was set at $+7 \mathrm{dBm}$. Both positioning of the 10 - 

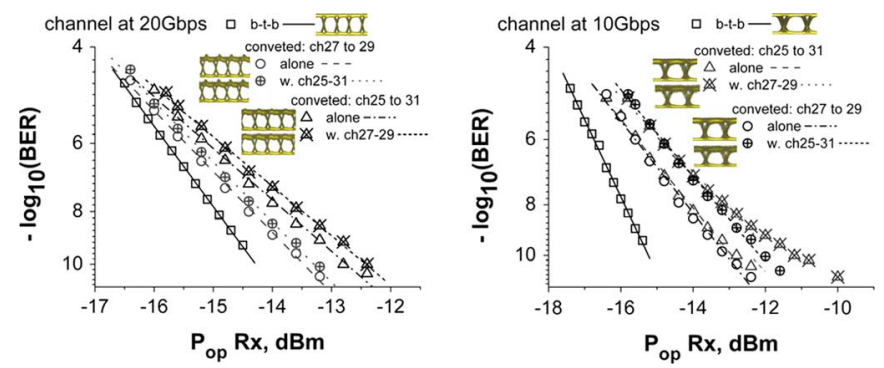

Fig. 3. Simultaneous lambda-conversion $20+10 \mathrm{~Gb} / \mathrm{s}$ ASK: eye diagrams and BER curves of 20 (left) and 10 (right) Gb/s channels.
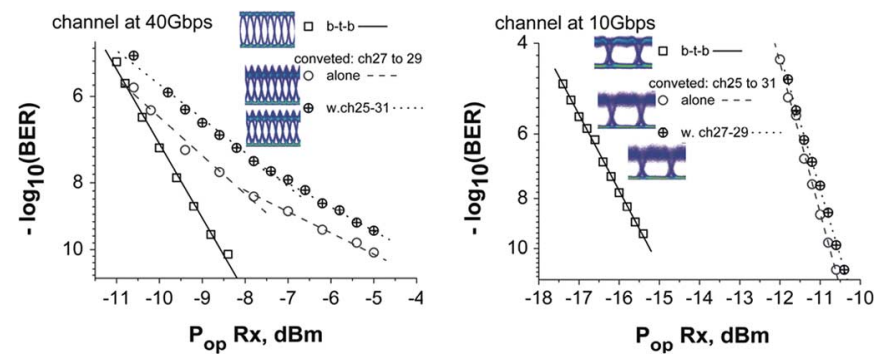

Fig. 4. Simultaneous lambda-conversion $40+10 \mathrm{~Gb} / \mathrm{s}$ ASK: eye diagrams and BER curves of 40 (left) and 10 (right) $\mathrm{Gb} / \mathrm{s}$ channels.

and $20-\mathrm{Gb} / \mathrm{s}$ input data channels with respect to the CW pump were tested: close to (conversion from channel \#27 to channel \#29) and apart (from channel \#25 to channel \#31). From Fig. 3, the $20-\mathrm{Gb} / \mathrm{s}$ channel presents error-free operation, with $1-\mathrm{dB}$ degradation of required optical power at the receiver for the same BER performance when being the closest $(100 \mathrm{GHz})$ to the CW probe.

When placed further away $(300 \mathrm{GHz})$, the power penalty increases to $2 \mathrm{~dB}$. A very small difference $(0.1-0.3 \mathrm{~dB})$ exists between single- and dual-channel operation modes. For the $10-\mathrm{Gb} / \mathrm{s}$ channel, when placed closer to the CW pump, a power penalty of $2 \mathrm{~dB}$ was measured for single conversion and an extra $1.1 \mathrm{~dB}$ in the dual-channel mode. When placed further away from the pump (ITU channel \#25), a power penalty of 2.2-dB penalty was observed and when a second channel (channel \#27) was turned ON simultaneously an error floor was observed around a BER $\sim 10^{-12}$; at a BER of $10^{-11}$, a $4-\mathrm{dB}$ penalty was obtained. The detected noise floor is mainly due the noise from spurious FWM over the converted channel and the limited OSNR.

For the $40+10 \mathrm{~Gb} / \mathrm{s}$ case (Fig. 4), the converted 40-Gb/s channel shows an error floor above $\mathrm{BER}=10^{-12}$ regardless of the presence of a second $10-\mathrm{Gb} / \mathrm{s}$ input channel. This noise floor is mostly the result of overshoots appearing at the higher ("1") bit level and the limited OSNR at the SOA's output.

A 4-dB total penalty was obtained at $\mathrm{BER}=10^{-11}$, with an added $1-\mathrm{dB}$ penalty when the second channel is turned $\mathrm{ON}$. The $10-\mathrm{Gb} / \mathrm{s}$ channel was measured to have a $4-\mathrm{dB}$ penalty due mostly to noise over the high-level (see on inset in Fig. 4) with no difference between the single- and the dual-channel operation.

For the case of simultaneous conversion of $40-$ and $10-\mathrm{Gb} / \mathrm{s}$ channels it was impossible to switch the respective positions of 40- and $10-\mathrm{Gb} / \mathrm{s}$ channels since the obtainable FWM efficiency and OSNR for the $40 \mathrm{~Gb} / \mathrm{s}$, when placed further away from the CW pump, could not deliver error-free operation.

\section{DISCUSSION AND CONCLUSION}

We have demonstrated an all-optical wavelength converter based on FWM phenomenon in a single SOA and single CW pump capable of simultaneously converting two different data streams with low input powers. For mixed modulation formats at $10-\mathrm{Gb} / \mathrm{s}$ negligible penalty was obtained and for mixed bit rates at speeds up to $40-\mathrm{Gb} / \mathrm{s}$ moderate penalties were found, all with minor dependency on the introduction of a second simultaneously converted channel $(<1.1 \mathrm{~dB})$. The ASK modulation did not result in XGM since the modulated signals at the SOA's input were more than $20 \mathrm{~dB}$ lower than the $\mathrm{CW}$ pump, insuring deep saturation of optical gain as well as allowing the desired degenerated FWM process to dominate. The CW and carrier's power should be optimize as a compromise between the FWM efficiency, ASE suppression, gain-clamping and the induced dynamic gain compression. Better performance could be obtained with lower noise SOAs, such as quantum-dot-based devices, or with a device enabling higher saturation power. In these cases, the strong optical gain and FWM efficiency should be maintained but the output OSNR improved. With the demonstrated minor degradation of power penalty when a second channel is introduced, the suggested scheme is suitable for many applications in all-optical routers, enabling asynchronous operation as well as operation with different modulation formats and bit rates up to $40 \mathrm{~Gb} / \mathrm{s}$.

\section{REFERENCES}

[1] S. L. Danielsen, P. B. Hansen, and K. E. Stubkjaer, "Wavelength conversion in optical packet switching," J. Lightwave. Technol., vol. 16, no. 12, pp. 2095-2108, Dec. 1998.

[2] H. J. S. Dorren et al., "A 3-stage CLOS architecture for highthroughput optical packet switching," in Proc. ACP, Shanghai, China, 2009, Paper FT6, Proc. SPIE, vol. 7632, p. 763229-1/6.

[3] V. Eramo, M. Listanti, and A. Germoni, "Cost evaluation of optical packet switches equipped with limited-range and full-range converters for contention resolution," J. Lightw. Technol., vol. 26, no. 4, pp. 390-407, Feb. 15, 2008.

[4] J. Yamawaku et al., "Selective wavelength conversion using PPLN waveguide with two pump configuration," in Conf. Lasers and ElectroOptics, Baltimore, MD, 2003, Paper CWB5.

[5] T. Tanemura, C. S. Goh, K. Kikuchi, and S. Y. Set, "Highly efficient arbitrary wavelength conversion within entire $C$-band based on nondegenerate fiber four-wave mixing," IEEE Photon. Technol. Lett., vol. 16, no. 2, pp. 551-553, Feb. 2004.

[6] Y. Liu et al., "Error-free $320 \mathrm{~Gb} / \mathrm{s}$ SOA-based wavelength conversion using optical filtering," in Proc. Optical Fiber Communication Conf., Anaheim, CA, 2006, Paper PDP28.

[7] X. Yi et al., "Modulation format independent conversion," in Proc. Optical Fiber Communication Conf., San Diego, CA, 2009, Paper PDPC8.

[8] T. Akiyama et al., "Nonlinear processes responsible for nondegenerate four-wave mixing in quantum-dot optical amplifiers," Appl. Phys. Lett., vol. 77, no. 12, pp. 1753-1755, 2000.

[9] G. Contestabile et al., "Transparency of FWM in SOAs to phase/amplitude and polarization," in Proc. Optical Fiber Communication Conf., San Diego, CA, 2009, Paper OThM6.

[10] J. P. R. Lacey, S. J. Madden, and M. A. Summerfield, "Four-channel polarization-insensitive optically transparent wavelength converter," IEEE Photon. Technol. Lett., vol. 9, no. 10, pp. 1355-1357, Oct. 1997.

[11] O. Raz et al., "Simultaneous penalty free dual wavelength conversion using four wave mixing in a semiconductor optical amplifier," in Proc. IEEE Photonics Society Annual Meeting, Belek Antalya, Turkey, 2009, Paper WK2.

[12] H. J. S. Dorren et al., "Scaling all-optical packet routers: How much buffering is required?," J. Opt. Netw., vol. 7, no. 11, pp. 936-946, 2008. 